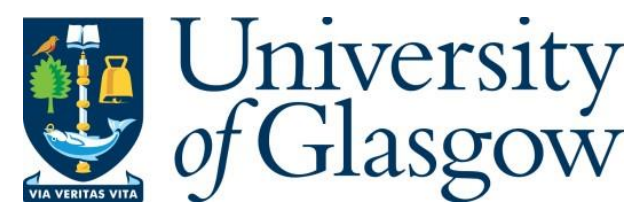

O'Hagan, J., Khamis, M. and Williamson, J. R. (2021) Surveying Consumer Understanding \& Sentiment Of VR. In: MMVE '21, Istanbul, Turkey, 28 Sep - 1 Oct 2021, pp. 14-20. ISBN 9781450384360

There may be differences between this version and the published version. You are advised to consult the publisher's version if you wish to cite from it.

(C) 2021 Copyright held by the owner/author(s). This is the author's version of the work. It is posted here for your personal use. Not for redistribution. The definitive Version of Record was published in MMVE '21: Proceedings of the International Workshop on Immersive Mixed and Virtual Environment Systems http://dx.doi.org/10.1145/3458307.3460965

http://eprints.gla.ac.uk/240318/

Deposited on: 28 April 2021

Enlighten - Research publications by members of the University of Glasgow http://eprints.gla.ac.uk 


\section{Surveying Consumer Understanding \& Sentiment Of VR}

\author{
Joseph O’Hagan \\ University of Glasgow, Scotland \\ j.ohagan.1@research.gla.ac
}

\author{
Mohamed Khamis \\ University of Glasgow, Scotland \\ mohamed.khamis@glasgow.ac.uk
}

\author{
Julie R. Williamson \\ University of Glasgow, Scotland \\ julie.williamson@glasgow.ac.uk
}

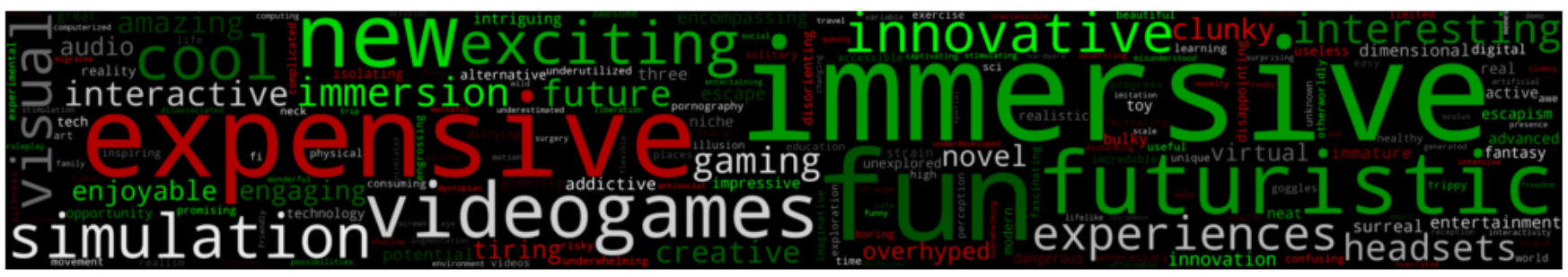

Figure 1: A word cloud visualisation of terms used by respondents in response to "Which 4 words would you use to describe virtual reality?” (green: positive sentiment words, white: neutral sentiment words, and red: negative sentiment words)

\begin{abstract}
Since the resurgence of consumer-grade virtual reality (VR), VR has successfully established itself on the consumer market. As with any emerging technology, differences can exist between how industry / academia view the technology and how consumers perceive it. We present results from a survey $(\mathrm{N}=210)$ conducted into consumer perception and attitudes towards VR. We report sentiment towards VR is positive. We show the associations linked with VR by our respondents match the defining characteristics of VR identified by experts in the literature (a fully virtual view, immersion, and headworn technology). We identify 3 additional concepts associated with VR by our respondents: video games, futurism, and price. However, our results also show consumer expectations for VR are fixated around "VR for gaming" and suggest VR has to an extent been pigeonholed as primarily being a gaming device.
\end{abstract}

\section{CCS CONCEPTS}

- Human-centered computing $\rightarrow$ Virtual reality.

\section{KEYWORDS}

Virtual Reality, Mixed Reality, Mental Models, Public Understanding, Perceptions

\section{ACM Reference Format:}

Joseph O'Hagan, Mohamed Khamis, and Julie R. Williamson. 2021. Surveying Consumer Understanding \& Sentiment Of VR. In International Workshop on Immersive Mixed and Virtual Environment Systems (MMVE '21) (MMVE '21), September 28-October 1 2021, Istanbul, Turkey. ACM, New York, NY, USA, 7 pages. https://doi.org/10.1145/3458307.3460965

MMVE '21, September 28-October 12021 , Istanbul, Turkey

(C) 2021 Copyright held by the owner/author(s). Publication rights licensed to ACM This is the author's version of the work. It is posted here for your personal use. Not for redistribution. The definitive Version of Record was published in International Workshop on Immersive Mixed and Virtual Environment Systems (MMVE '21) (MMVE '21), September 28-October 1 2021, Istanbul, Turkey, https://doi.org/10.1145/3458307.3460965.

\section{INTRODUCTION}

Since the 2010s resurgence of interest in consumer-grade virtual reality (VR) [48], VR has successfully established itself on the consumer market [47]. However, as with any emerging technology, differences can exist between how industry / academia perceive a technology and how consumers perceive it $[49,50]$. While it is unlikely individuals will share an identical understanding of any technology it remains necessary to "know thy user" [10] when considering future design innovations. Failure to understand the user's mental model and perception of a system can create dissonance between the designer and user resulting in the development of an unsuccessful system $[2,14-17]$.

We present the results of a survey $(\mathrm{N}=210)$ which explored consumer perception and sentiment towards VR. We investigated the associations linked with VR by our respondents and compared them with experts' definition of VR from the literature. Unlike augmented reality (AR) which is not well understood by consumers $[49,50]$, we show that VR appears to be well understood by our respondents. All 3 of the defining characteristics of VR identified by experts (" $a$ fully virtual view", "full immersion" and "head-worn technology") [42] were associated with VR by our respondents. We highlight 3 additional concepts ("video games", "price", and "futurism") our respondents also associate with VR. To further investigate how experience with VR changed respondents' perception of VR, we split our data using respondents' self assessed prior experience with VR score. This produced a data set of inexperienced respondents $(\mathrm{N}=89)$ and a data set of experienced respondents $(\mathrm{N}=67)$. We found both inexperienced and experienced respondents associate and describe VR using similar concepts. Similar results were also found when analysing sentiment towards VR: a positive sentiment by the general response and by both the inexperienced and experienced subgroups. 


\section{RELATED WORK}

\subsection{Augmented, Mixed \& Virtual Realities}

VR has become an increasingly popular topic within the HCI community in recent years. A survey of the $\mathrm{CHI} 2019$ proceedings [44] found $94(13.3 \%)$ conference papers on the topic alone. Most work in the topic utilises Milgram's Reality-Virtuality Continuum [29, 30] when defining and discussing the concepts of AR, mixed reality (MR) and VR. Speicher et al. noticing discrepancies within the literature of how the term MR is used interviewed experts from academia / industry and surveyed the literature to highlight the lack of agreed upon definition of MR [42]. Speicher et al. identified six partially competing notions to answer their question "What is mixed reality?" ultimately concluding "it depends". However, Speicher et al. did find experts generally agreed on a definition of what constitutes VR - $a$ fully virtual view, full immersion and head-worn technology.

Regardless of unity in expert opinion, large inconsistencies can exist between expert and consumer understanding of a system. Unlike expert discussion around defining AR which focuses on the technicalities of similar concepts, confusion remains within consumers of what AR actually is and does [49]. Despite AR being increasingly used for entertainment, promotional and educational purposes [20,31,38] consumer understanding of AR is poor [50]. At present it is unknown how consumers perceive VR. While some work has examined its use in specific contexts [37] or discussed it's contribution over time [4] none has investigated understanding or perception directly. As technologies such as AR, MR and VR become more prevalent and sophisticated it is increasingly important to understand users' attitudes, understanding and perception of them. Failure to understand these can create dissonance between user expectations and built systems, ultimately resulting in the production of unsuccessful systems [2,14].

\subsection{Mental Models}

Mental models are conceptual models in people's minds which represent their understanding of how things work [32]. As individuals construct their own mental models, models of the same item can differ and individuals may utilise more than one model of a system to consolidate different functions $[32,43]$. These models are not predefined or chosen by the individual rather they are intuitively created by the individual [15]. An individual's mental model of an information system has been shown to influence the individuals' ability to learn the system [43]. Staggers \& Norcio highlighted the use of analogy, metaphor and experience with similar systems when individuals construct a mental model of a system [43]. This model is then used by the individual to describe and mentally test the system. However, Staggers \& Norcio also highlighted such mental models can be incomplete, inaccurate or overgeneralised [43]. The potential for such variation and abstraction in mental models motivates the need to understand users' mental models when developing technologies with HCI components.

\subsection{Consumer Perception}

Consumer perception of a product is the set of perceptions about the product as reflected by the associations the consumer links with the product $[16,17]$. It is the set of beliefs held by the consumer about the product [16]. Like mental models these cannot be predefined or chosen. Instead they originate from consumers (and their perception of a product) and are difficult for a company to govern [17]. However, a positive consumer perception is essential for a successful and long term product $[2,14]$.

Understanding users' perception of products is essential when developing technologies with human-computer components. Such work can identify if a mismatch exists between consumer perception and understanding of a product and the views held by industry and academia. Investigating user perception also contributes towards understanding users' mental models of the product. A user's mental model and perception of a system cannot be chosen or governed [15]. However, by investigating and understanding the users' understanding and perception of the system we can build systems to challenge user's beliefs of the system and potentially even change their mental model and perception of the system.

\section{SURVEY DESIGN}

We developed a survey to investigate consumer understanding and attitudes towards VR. Our survey consisted of 2 open questions and 6 binary choice (Yes / No) questions. We only report on the 2 open questions within this paper as these were the only questions in our survey which investigated the concepts respondents associate with VR / assessed their sentiment towards VR (the subject of this paper). The omitted questions all occurred after the questions analysed in this paper which were at the start of the survey so did not influence how respondents answers the analysed questions.

Our survey first asked "When you think of virtual reality what first comes to mind?" to identify concepts the respondent associates VR with. We then asked "Which 4 words would you use to describe virtual reality?”. Both are common approaches to investigate concepts associated with a subject and sentiment towards it. We restricted respondents to 4 words to allow for comparisons between responses and to force respondents to curate their choice of words rather than list every word they could think of. This approach to questioning was derived from recommendations in the literature [7, 15, 40, 43]. The survey took approximately 3-5 minutes to complete. Respondents did not require prior experience with VR to answer.

\subsection{Limitations}

We targeted a general population, with a wide range of prior experience with VR, to capture a broad insight into the current perception and understanding of VR. Future work could target specific subgroups of individuals (e.g. people who work with VR in industry, etc) and compare these directly. Additionally, there are many methods of investigating users' understanding of VR. Our approach restricted respondents to pick 4 words to describe VR, however, a more open approach could have been taken. We could have asked "In your own words how would you define virtual reality?" to obtain a more direct insight of respondents' mental model and future work could investigate this more open approach. It could also ask respondents to compare different technologies directly (VR, AR and MR systems) and investigate whether they can identify examples of each technology to increase our knowledge of consumer understanding of extended reality technologies. 


\begin{tabular}{|l|r|r|}
\hline All respondents \\
\hline Theme & $\begin{array}{c}\text { Referenced } \\
\text { by (of 210) }\end{array}$ & $\begin{array}{c}\text { As } \\
\text { Percentage }\end{array}$ \\
\hline Applications of VR & 99 & $41.14 \%$ \\
\hline Hardware & 77 & $36.66 \%$ \\
\hline Another World & 36 & $17.14 \%$ \\
\hline Immersion & 27 & $12.86 \%$ \\
\hline Futurisim & 19 & $9.05 \%$ \\
\hline Opinions of VR & 18 & $8.57 \%$ \\
\hline VR in Media & 14 & $6.67 \%$ \\
\hline Price & 8 & $3.81 \%$ \\
\hline The VR User & 7 & $3.33 \%$ \\
\hline Unfamiliarity With VR & 5 & $2.38 \%$ \\
\hline Simulation Sickness & 5 & $2.38 \%$ \\
\hline
\end{tabular}

Inexperienced respondents
\begin{tabular}{|l|r|r|}
\hline Theme & $\begin{array}{c}\text { Referenced } \\
\text { by (of 89) }\end{array}$ & $\begin{array}{c}\text { As } \\
\text { Percentage }\end{array}$ \\
\hline Applications of VR & 43 & $48.31 \%$ \\
\hline Hardware & 32 & $35.96 \%$ \\
\hline Another World & 15 & $16.85 \%$ \\
\hline Immersion & 8 & $8.99 \%$ \\
\hline Futurisim & 6 & $6.74 \%$ \\
\hline Opinions of VR & 6 & $6.74 \%$ \\
\hline VR in Media & 7 & $7.87 \%$ \\
\hline Price & 4 & $4.49 \%$ \\
\hline The VR User & 2 & $2.25 \%$ \\
\hline Unfamiliarity With VR & 5 & $5.62 \%$ \\
\hline Simulation Sickness & 2 & $2.25 \%$ \\
\hline
\end{tabular}

Experienced respondents
\begin{tabular}{|l|r|r|}
\hline Theme & $\begin{array}{c}\text { Referenced } \\
\text { by }(\mathbf{o f} 67)\end{array}$ & $\begin{array}{c}\text { As } \\
\text { Percentage }\end{array}$ \\
\hline Applications of VR & 29 & $43.28 \%$ \\
\hline Hardware & 30 & $44.78 \%$ \\
\hline Another World & 10 & $14.93 \%$ \\
\hline Immersion & 11 & $16.42 \%$ \\
\hline Futurism & 7 & $10.45 \%$ \\
\hline Opinions of VR & 3 & $4.48 \%$ \\
\hline VR in Media & 5 & $7.46 \%$ \\
\hline Price & 2 & $2.99 \%$ \\
\hline The VR User & 3 & $4.48 \%$ \\
\hline Unfamiliarity With VR & 0 & $0 \%$ \\
\hline Simulation Sickness & 0 & $0 \%$ \\
\hline
\end{tabular}

Table 1: The 11 themes of association identified from answers to "When you think of virtual reality what first comes to mind?". Referenced by indicates the number of respondents who referenced the theme in their response. Multiple coding was allowed so 1 respondent can be associated with multiple themes.

\section{ANALYSIS PROCEDURE}

We analysed our data to investigate the general response of our respondents $(\mathrm{N}=210)$. Respondent answers were coded using initial coding [5] where respondents' statements were assigned emergent codes over repeated cycles with the codes grouped using a thematic approach. A single coder performed the coding. Three coding cycles were completed. In addition to the thematic coding, sentiment analysis was performed on the 4 words data set respondents used to describe VR. This produced a sentiment score to indicate whether our respondents thought of VR positively or negatively and the frequency with which terms were used by respondents. We then investigated how experience with VR might change our results and split our data by respondents' self assessed prior experience with VR score. The analysis process outlined above was repeated for both subgroups (inexperienced $\mathrm{N}=89$, experienced $\mathrm{N}=67$ ).

\section{DEMOGRAPHIC DATA}

We distributed the survey through mailing lists and social media. 210 respondents (65 female, 127 male, 10 other, 8 prefer not to say) aged between 16 and $66(\mathrm{M}=25.33, \mathrm{SD}=9.80)$ completed the survey. Respondents were asked to indicate their prior experience with VR headsets using a 5-point Likert scale ( $1=$ none; $5=$ a lot), $(\mathrm{M}=3.04, \mathrm{SD}=1.23)$. To investigate how prior experience with VR might change respondents' perception of VR we split our data using the respondents' self assessed prior experience with VR score. This resulted in a data set of 89 respondents who identified as having "None" or "A little" experience with VR and a data set of 67 respondents with "Much" or "A lot" of experience with VR. The remaining 54 respondents who indicated they had "Some" experience (the mid-value on our scale) were omitted. The inexperienced data set $(\mathrm{N}=89)$ (39 female, 42 male, 3 other, 5 prefer not to say) were aged between 16 and $66(M=26.25, S D=10.52)$. Prior experience with VR consisted of $(\operatorname{None}(1)=11$, A little $(2)=78)$ with $M=1.88$ and $S D=0.33$. The more experienced data set $(\mathrm{N}=67)$ ( 7 female, 51 male, 6 other, 3 prefer not to say) were aged between 16 and $54(\mathrm{M}=26.34, \mathrm{SD}=10.49)$. Prior experience with VR consisted of $(\operatorname{Much}(4)=25, \operatorname{A} \operatorname{lot}(5)=42)$ with $M=4.63$ and $\mathrm{SD}=0.49$.

\section{IMMEDIATE RESPONSE \& ASSOCIATED CONCEPTS}

Our survey first asked respondents "When you think of virtual reality what first comes to mind?" to elicit which concepts respondents associate with VR. Answers were thematically encoded where individual responses could contain multiple themes (e.g. P34: "VR headsets for games" was counted as containing both the Applications of VR and Hardware themes). Table 1 shows the frequency themes occurred within responses. The 11 themes identified were:

- Applications of VR: applications or use cases of VR (with a strong association between VR and video games / gaming which featured in 95 of the 99 responses in this theme)

- Hardware: descriptions of hardware used to experience VR

- Another World: associating VR with going to or being in "another world / artificial environment"

- Immersion: suggest VR is an immersive technology

- Futurism: suggest VR is a futuristic / high-tech technology

- Opinions of VR: express opinions held about VR from past experience with it

- VR in Media: gave examples of VR in media

- Price: comments on how expensive equipment is

- The VR User: refer to the visual image of someone using a VR headset

- Unfamiliarity With VR: indicating an unfamiliarity of VR/ VR technology

- Simulation Sickness: descriptions of issues experienced while using VR relating to simulation sickness

Comparing the associations linked with VR by our respondents with the 3 concepts experts' identify as defining VR (a fully virtual view, full immersion, head-worn technology) [42] we find that all 3 are associated with VR by our respondents. Our Hardware theme shows our respondents are aware of how VR is currently experienced and our Another World and Immersion themes show they associate it with being a fully virtual, immersive experience.

Prior experience with VR had no influence on which concepts our respondents associate with VR - both our inexperienced and experienced subgroup of respondents associated VR with similar concepts. The largest difference was the more frequent reference to our Hardware theme by experienced respondents which may be justified by experienced users being more likely to reference VR hardware they own or have used. Surprisingly, more responses 


\begin{tabular}{|l|r|r|r|}
\multicolumn{5}{|c|}{ All respondents } \\
\hline Theme & $\begin{array}{l}\text { Unique Terms } \\
\text { Within Theme }\end{array}$ & $\begin{array}{c}\text { Count } \\
\text { (of 840) }\end{array}$ & $\begin{array}{c}\text { As } \\
\text { Percentage }\end{array}$ \\
\hline Hardware & 43 & 116 & $13.81 \%$ \\
\hline Application of VR & 21 & 76 & $9.05 \%$ \\
\hline Other & 34 & 67 & $7.97 \%$ \\
\hline
\end{tabular}

\begin{tabular}{|l|r|r|}
\hline \multicolumn{1}{|c|}{ Inexperienced respondents } \\
\hline Theme & $\begin{array}{c}\text { Count } \\
\text { (of 356) }\end{array}$ & $\begin{array}{c}\text { As } \\
\text { Percentage }\end{array}$ \\
\hline Hardware & 45 & $12.64 \%$ \\
\hline Application of VR & 30 & $8.43 \%$ \\
\hline Other & 21 & $5.90 \%$ \\
\hline
\end{tabular}

\begin{tabular}{|l|r|r|}
\multicolumn{3}{|c|}{ Experienced respondents } \\
\hline Theme & $\begin{array}{c}\text { Count } \\
\text { (of 268) }\end{array}$ & $\begin{array}{c}\text { As } \\
\text { Percentage }\end{array}$ \\
\hline Hardware & 34 & $12.69 \%$ \\
\hline Application of VR & 30 & $11.19 \%$ \\
\hline Other & 29 & $10.82 \%$ \\
\hline
\end{tabular}

Table 2: The 3 descriptive themes identified from answers to "Which 4 words would you use to describe virtual reality?"

\begin{tabular}{|l|r|r|r|}
\multicolumn{5}{c|}{ All respondents } \\
\hline Theme & $\begin{array}{l}\text { Unique Terms } \\
\text { Within Theme }\end{array}$ & $\begin{array}{c}\text { Count } \\
\text { (of 840) }\end{array}$ & $\begin{array}{c}\text { As } \\
\text { Percentage }\end{array}$ \\
\hline Positive Critique & 36 & 178 & $21.19 \%$ \\
\hline Immersive & 17 & 125 & $14.88 \%$ \\
\hline Futurism & 17 & 112 & $13.33 \%$ \\
\hline Negative Critique & 20 & 78 & $9.28 \%$ \\
\hline Disappointing & 21 & 46 & $5.47 \%$ \\
\hline $\begin{array}{l}\text { Simulation Sickness / } \\
\text { Usage Issues }\end{array}$ & 13 & 21 & $2.50 \%$ \\
\hline Complex & 9 & 13 & $1.55 \%$ \\
\hline Social & 5 & 8 & $0.95 \%$ \\
\hline
\end{tabular}

Inexperienced respondents
\begin{tabular}{|l|r|r|}
\hline Theme & $\begin{array}{c}\text { Count } \\
\text { (of 356) }\end{array}$ & $\begin{array}{c}\text { As } \\
\text { Percentage }\end{array}$ \\
\hline Positive Critique & 71 & $19.94 \%$ \\
\hline Immersive & 51 & $14.33 \%$ \\
\hline Futurism & 46 & $12.92 \%$ \\
\hline Negative Critique & 43 & $12.08 \%$ \\
\hline Disappointing & 24 & $6.74 \%$ \\
\hline $\begin{array}{l}\text { Simulation Sickness / } \\
\text { Usage Issues }\end{array}$ & 15 & $4.21 \%$ \\
\hline Complex & 7 & $1.97 \%$ \\
\hline Social & 3 & $0.84 \%$ \\
\hline
\end{tabular}

Experienced respondents
\begin{tabular}{|l|r|r|}
\hline Theme & $\begin{array}{c}\text { Count } \\
\text { (of 268) }\end{array}$ & $\begin{array}{c}\text { As } \\
\text { Percentage }\end{array}$ \\
\hline Positive Critique & 55 & $20.52 \%$ \\
\hline Immersive & 42 & $15.67 \%$ \\
\hline Futurism & 36 & $13.44 \%$ \\
\hline Negative Critique & 16 & $5.97 \%$ \\
\hline Disappointing & 15 & $5.60 \%$ \\
\hline Simulation Sickness / & 4 & $1.49 \%$ \\
Usage Issues & 4 & $1.12 \%$ \\
\hline Complex & 3 & $1.49 \%$ \\
\hline Social & 4 & \\
\hline
\end{tabular}

Table 3: The 8 subjective themes identified from answers to "Which 4 words would you use to describe virtual reality?"

which associated VR with the Futurism theme were made by our more experienced respondents. Although the difference in proportion is minor it is still unusual to consider individuals experienced with a technology consider it futuristic. This could indicate consumers still think of VR as being some way from achieving its true potential and that VR is seen as being not fully relevant right now. Certainly users with more expansive usage of VR will be more familiar with the current limitations of the technology [11, 39] and may simply be optimistic of its potential. Future work could explore this idea in more detail.

\section{DESCRIPTION TERMS \& SENTIMENT ANALYSIS}

We then asked respondents "Which 4 words would you use to describe virtual reality?". Prior to analysis the data was cleaned where appropriate to ensure all responses were in a valid input format of (word, word, word, word). For example, minor corrections were made such as the removal of superfluous characters like full stops (e.g. "immersive." changed to "immersive"). Any obvious typos were corrected (e.g. "immerson" corrected to "immersion"). Joining terms between words were removed (e.g. "new, immersive, fun and expensive" corrected to "new, immersive, fun, expensive"). All terms were converted to lowercase so that "Immersive" and "immersive" would be counted as occurrences of the same term. A frequency count was performed to calculate the total number of occurrences of each unique term and to generate a list of unique terms. Of the 840 terms analysed there was 236 unique terms. This list of 236 unique terms was used to produce a sentiment mapping for every term in our data. A single coder reviewed each term and assigned it a sentiment score of either Positive (+1), Neutral (0) or Negative (-1). Each term was also assigned emergent codes over repeated cycles with the codes grouped using a thematic approach. Three coding cycles were completed.

\subsection{Themes:}

Thematic analysis was used to investigate emergent themes within the terms. 2 general categories of term emerged: subjective (138 terms) and descriptive (98 terms). This split in subjective and descriptive terms was used to assist with the sentiment analysis where descriptive terms corresponded to the set of neutral terms and subjective terms formed the positive and negative sets. Within these general categories we identified 3 themes of descriptive terms and 8 themes of subjective terms. Terms were unique to each theme. The 3 themes within the descriptive group (Table 2) were:

- Hardware: descriptions of the hardware used to experience VR (e.g. "oculus" or "headsets") or terms associated with experiences the hardware creates (e.g. "virtual" or "interactivity").

- Applications of VR: applications or use cases of VR (e.g. "entertainment" or "videos").

- Other: used as a general catch-all for descriptive terms (e.g. "alternative" or "fantasy") and other terms with a neutral sentiment (e.g. "surprising").

The 8 themes within the subjective group (Table 3) were:

- Positive Critique: general positive comments about VR (e.g. "great" or "fun")

- Immersive: suggest VR is an immersive experience (e.g. "immersive")

- Futurism: suggest respondents perceive VR as a futuristic / innovative technology (e.g. "futuristic" or "progress")

- Negative Critique: general negative critiques and comments about VR (e.g. "stupid" or "useless")

- Disappointing: suggest respondents were disappointed by their experience with VR (e.g. "overhyped" or "disappointing") or felt the technology had yet to fully mature (e.g. "clunky" or "rough")

- Simulation Sickness / Usage Issues: issues experienced while using VR (e.g. "headaches" / "neck-strain")

- Complex: suggest respondents found VR complex or difficult to use (e.g. "overwhelming" or "inaccessible")

- Social: refer to perceived social use / impact of VR (e.g. "social" or "isolating”)

The high frequency respondents mentioned hardware or applications of VR (Table 2) reinforce these as strong associations linked with VR, accounting for $22.86 \%$ of the terms used to describe VR. The emergence of themes relating to VR being immersive $(14.88 \%$ 


\begin{tabular}{|l|r|r|}
\hline Term & $\begin{array}{l}\text { Count } \\
\text { (of 840) }\end{array}$ & Sentiment \\
\hline immersive & 76 & Positive \\
\hline fun & 57 & Positive \\
\hline expensive & 49 & Negative \\
\hline new & 28 & Positive \\
\hline futuristic & 26 & Positive \\
\hline videogames & 20 & Neutral \\
\hline cool & 18 & Positive \\
\hline exciting & 17 & Positive \\
\hline simulation & 17 & Neutral \\
\hline innovation & 15 & Positive \\
\hline
\end{tabular}

Inexperienced respondents
\begin{tabular}{|l|r|r|}
\hline Term & $\begin{array}{l}\text { Count } \\
\text { (of 356) }\end{array}$ & Sentiment \\
\hline immersive & 35 & Positive \\
\hline expensive & 22 & Negative \\
\hline fun & 17 & Positive \\
\hline new & 15 & Positive \\
\hline futuristic & 14 & Positive \\
\hline exciting & 9 & Positive \\
\hline gaming & 7 & Neutral \\
\hline experiences & 6 & Neutral \\
\hline innovative & 6 & Positive \\
\hline headsets & 6 & Neutral \\
\hline
\end{tabular}

Experienced respondents
\begin{tabular}{|l|r|r|}
\hline Term & $\begin{array}{l}\text { Count } \\
\text { (of 268) }\end{array}$ & Sentiment \\
\hline immersive & 26 & Positive \\
\hline fun & 17 & Positive \\
\hline expensive & 16 & Negative \\
\hline new & 10 & Positive \\
\hline videogames & 7 & Neutral \\
\hline futuristic & 7 & Positive \\
\hline cool & 6 & Positive \\
\hline simulation & 6 & Neutral \\
\hline immersion & 5 & Positive \\
\hline exciting & 5 & Positive \\
\hline
\end{tabular}

Table 4: The 10 most frequently used terms to describe VR in answer to "Which 4 words would you use to describe virtual reality?”

of the terms used to describe VR) and futuristic (13.33\% of the terms used to describe VR) again highlights these as concepts linked with VR by our respondents. The set of "negative response themes" (Negative Critique, Disappointing, Simulation Sickness / Usage Issues, Complex) is worth considering as an opportunity for future work. Totalling $18.8 \%$ of the terms used to describe VR, each represents a different way VR has disappointed a potential user but also a different topic for future investigation. Future work could develop a more in-depth understanding of each theme and investigate if solutions can be built to rectify individuals' problems with VR (e.g. on-going work to improve simulation sickness [18, 19, 23, 25, 26]).

\subsection{Sentiment Score:}

The sentiment mapping produced a list of 70 unique positive terms, 98 unique neutral terms and 68 unique negative terms. This was used to calculate the sentiment score for all responses. The total score (of a possible 840 ) was $249(+29.64 \%)$ composed of a positive sum of $415(+49.41 \%)$, a neutral sum of $259(30.83 \%)$ and a negative sum of $-166(-19.76 \%)$. The inexperienced subgroup total score (of a possible 356) was $76(+21.35 \%)$ composed of a positive sum of $168(+47.19 \%)$, a neutral sum of $96(26.97 \%)$ and a negative sum of -92 (-25.84\%). The experienced subgroup total score (of a possible $268)$ was $91(+33.96 \%)$ composed of a positive sum of $133(+49.63 \%)$, a neutral sum of $93(34.70 \%)$ and a negative sum of $-42(-15.67 . \%)$. Comparing the two there is a difference of $12.61 \%$ primarily due to the difference in negative responses (inexperienced: $-25.84 \%$, experienced: $-15.67 \%$ ). The positive proportions were similar (inexperienced: $+47.19 \%$, experienced: $+49.63 \%$ ).

\subsection{Frequency Count:}

Examining the 10 most frequently occurring terms (Table 4) provides a good overview of how our respondents view VR. VR is described as "fun", "cool", "exciting", "innovation" which are all positive qualities. Its description as "immersive” highlights current VR headsets provide experiences our respondents consider immersive or that our respondents acknowledge immersion is a goal of VR. The description of "expensive" highlights the perceived high cost of the technology which may deter some from purchasing VR devices. Both "videogames" and "simulation(s)" are frequently referenced applications of VR. Surprisingly, despite consumer VR headsets being available for 5+ years they are still described as "new" and "futuristic". While we view this as a positive attribute it is an interesting observation of how VR is currently viewed. Despite versions of VR existing since at least the 1960s $[6,45,46]$ and much media attention throughout the 2010s [1] VR remains a "futuristic" concept for some.

Comparing the 10 most frequently used terms across respondent experience levels (Table 4), 7 occur in all respondent subgroups (immersive, fun, expensive, new, futuristic, exciting) in all and "gaming" and "videogames" (synonymous terms) also appearing. All subgroups share the 4 most frequently occurring terms (immersive, fun, expensive, new) although the ordering varies in the inexperienced subgroup.

\section{DISCUSSION}

We found VR was well understood by our respondents. All of VR's defining characteristics identified by experts (a fully virtual view, immersion, and head-worn technology) [42] were referenced frequently by our respondents. This is a positive result, especially when paired with the positive sentiment towards VR found in our survey, and should be seen as encouraging for those working in the medium. Furthermore, in our first question we found 8 additional concepts associated with VR by our participants. Of these, due to their high occurrence in our second question, we identify "video games", "futurism", and "price" as being 3 additional characteristics associated with VR by our respondents. While not defining characteristics of the medium they do provide insights into how VR is currently viewed by consumers.

\subsection{Fixation on VR for gaming}

Despite our respondents showing a good conceptual understanding of VR, their view of its application was significantly more limited. While research often presents VR as having a wide range of applications [3, 8, 9, 21, 24, 27, 36, 52] our respondents were significantly more limited in their range of referenced applications. Of the 99 responses in our first question which included an application of VR, 95 mentioned "video games" or "gaming" in some capacity. Similar results were seen in our second question also where "videogames" and "gaming" were frequently used by respondents to describe VR. The frequent reference to video games / gaming highlights the dominance of this use case within consumer perception of VR and suggests VR has yet to move beyond being "headsets used for video games". While gaming was the largest, and most open, market for VR to establish itself with consumers, its slow diversification from this may have pigeonholed it, to some extent, as being solely a gaming device in the eye's of consumers. For many, VR may be 
seen as an evolution or alternative to a video game console (e.g. a PlayStation) rather than a PC, that is, a device whose priority is gaming rather than a general purpose device capable of gaming. This fixation on "VR for gaming" is a limitation of the technology and suggests consumers may not yet fully grasp VR's potential beyond gaming. Many may not even know the full extent of their existing headset's capability beyond gaming applications and future work could survey VR usage and investigate which types of applications are used by headset owners and their awareness of the range of application types available to them.

\subsection{Beyond VR \& AR as independent concepts}

We investigated VR but consumer AR and MR technologies are becoming increasingly widespread. While research relates these concepts to one another through Milgram's reality-virtuality continuum $[29,30]$ it is unknown how (or if) consumers relate these concepts to one another. Is Milgram's continuum an intuitive relationship inferred by consumers or have alternative models emerged (if at all)? It may be that consumers view AR, VR and MR as independent, unrelated technologies.

While current consumer AR, VR and MR systems present users with experiences fixed at one position of Milgram's continuum, future systems will be capable of transitioning in real-time from one position on the continuum to another [13, 22, 34]. However, how these devices will be viewed by consumers remains unknown. Thompson et al. showed AR is currently not well understood by consumers $[49,50]$ while our works suggests VR is well understood. The introduction of systems which can transition from VR to AR (or vice versa) in real-time introduces additional complexity which will challenge consumers' current understanding of these technologies. If consumer fail fully understand them it can impact the adoption and success of them [14-17].

Currently, work which has explored these transitional devices $[13,22]$ has positioned them to consumers as being extensions of the safety notifications already present in existing consumer VR headsets (e.g. the Vive Chaperone [51] and Oculus Passthrough View [33]). Some feature significant augmentations of the VR user's surrounding reality into the VR scene [12, 13, 22] while others attempt to introduce the minimal amount of reality necessary to achieve some aim (e.g. notification of a bystander's entrance into the nearby area $[28,34,35,41])$. What remains unknown however is how consumers view these augmented VR experiences. Do they recognise that these VR experiences, now augmented with some element of the user's surrounding reality, are no longer "pure VR" experiences and have become augmented virtuality / mixed reality experiences? Or do they still consider them to be VR experiences despite the augmentation of reality within them? If the latter, this might influence their response to the system.

For example, McGill et al. investigated increasing a VR user's awareness of nearby peripherals and bystanders by augmenting a photoreal silhouette of the peripherals / bystander into the VR user's virtual environment [22]. Their results found participants were accepting of peripheral inclusion but rejected bystander inclusion as being too distracting to the user's experience in VR. However, the extent to which this result is because of how participants viewed the system is unknown. Would framing the experiment as a mixed reality system instead of being to "investigate increasing $a V R$ user's awareness of their surrounding reality from within $V R$ ” have influenced the participants' responses? Our study found consumers associated VR with immersion - where the goal is often to minimise disruptions from the user's surrounding reality. Perhaps McGill et al's participants were accepting of some augmentations of reality within VR (e.g. peripherals) which they viewed as being necessary inclusions and disruptions due to the limitations of the technology but rejected others (e.g. bystanders) as being superfluous for their usage of VR. In addition to further investigating consumer understanding of VR, future work should also consider to what extent the user's perception of what the system is (VR, AR or MR) influences their response to it.

\section{CONCLUSION}

This paper presents findings from work which investigated consumer perception and understanding of VR. We report sentiment towards VR is positive and show there is a good consumer understanding of VR. Associations linked with VR by our respondents match the defining characteristics of VR identified by experts in the literature (a fully virtual view, immersion, and head-worn technology). We identify 3 additional concepts linked with VR by our respondents (video games, price, futurism), however, we also report consumer expectations for VR are fixated on "VR for gaming" and suggest VR has to an extent been pigeonholed as primarily a gaming device.

\section{REFERENCES}

[1] Archive.org. 2020. Archive.org TV News Archive (search for VR in captions data). https://archive.org/details/tv?q=Virtual+Reality. Accessed: 2020-09-01.

[2] Grete Birtwistle and Linda Shearer. 2001. Consumer perception of five UK fashion retailers. Fournal of Fashion Marketing and Management 5, 1 (2001), 9-18. https://doi.org/10.1108/EUM0000000007275

[3] E. Chapoulie, R. Guerchouche, P. Petit, G. Chaurasia, P. Robert, and G. Drettakis. 2014. Reminiscence Therapy using Image-Based Rendering in VR. In 2014 IEEE Virtual Reality (VR). 45-50.

[4] Pietro Cipresso, Irene Alice Chicchi Giglioli, Mariano Alcaniz Raya, and Giuseppe Riva. 2018. The Past, Present, and Future of Virtual and Augmented Reality Research: A Network and Cluster Analysis of the Literature. Frontiers in Psychology 9 (2018), 2086. https://doi.org/10.3389/fpsyg.2018.02086

[5] Strauss A. L. Corbin J. M. 1998. Basics of qualitative research: techniques and procedures for developing grounded theory. SAGE Publications, Inc.

[6] Clark Dodsworth (Ed.). 1998. Digital Illusion: Entertaining the Future with High Technology. ACM Press/Addison-Wesley Publishing Co., USA.

[7] Sara Dolnicar, John R. Rossiter, and Bettina Grün. 2012. 'Pick Any' Measures Contaminate Brand Image Studies. International fournal of Market Research 54, 6 (2012), 821-834. https://doi.org/10.2501/IJMR-54-6-821-834 arXiv:https://doi.org/10.2501/IJMR-54-6-821-834

[8] Ruofei Du, David Li, and Amitabh Varshney. 2019. Geollery: A Mixed Reality Social Media Platform (CHI '19). Association for Computing Machinery, New York, NY, USA, 1-13. https://doi.org/10.1145/3290605.3300915

[9] David Englmeier, Joseph O’Hagan, Mengyi Zhang, Florian Alt, Andreas Butz, Tobias Höllerer, and Julie Williamson. 2020. TangibleSphere - Interaction Techniques for Physical and Virtual Spherical Displays. In Proceedings of the 11th Nordic Conference on Human-Computer Interaction: Shaping Experiences, Shaping Society (Tallinn, Estonia) (NordiCHI '20). Association for Computing Machinery, New York, NY, USA, Article 75, 11 pages. https://doi.org/10.1145/3419249.3420101

[10] Usability First. 2020. Usability First: Know Thy User. https://www.usabilityfirst. com/glossary/know-thy-user/index.html. Accessed: 2020-09-01.

[11] Alberto Gallace, Mary Ngo, J. Sulaitis, and Charles Spence. 2012. Multisensory presence in virtual reality: Possibilities and limitations. Multiple Sensorial Media Advances and Applications: New Developments in MulSeMedia (01 2012), 1-40.

[12] Ceenu George, Philipp Janssen, David Heuss, and Florian Alt. 2019. Should I Interrupt or Not?: Understanding Interruptions in Head-Mounted Display Settings. In Proceedings of the 2019 on Designing Interactive Systems Conference (San Diego, CA, USA) (DIS '19). ACM, New York, NY, USA, 497-510. https://doi.org/10.1145/3322276.3322363 
[13] C. George, A. N. Tien, and H. Hussmann. 2020. Seamless, Bi-directional Transitions along the Reality-Virtuality Continuum: A Conceptualization and Prototype Exploration. In 2020 IEEE International Symposium on Mixed and Augmented Reality (ISMAR). 412-424. https://doi.org/10.1109/ISMAR50242.2020.00067

[14] Ming-Huei Hsieh, Shan L Pan, and Rudy Setiono. 2004. Product-, Corporate-, and Country-Image Dimensions and Purchase Behavior: A Multicountry Analysis. Journal of The Academy of Marketing Science - f ACAD MARK SCI 32 (07 2004), 251-270. https://doi.org/10.1177/0092070304264262

[15] P. N. Johnson-Laird. 1986. Mental Models: Towards a Cognitive Science of Language, Inference, and Consciousness. Harvard University Press, USA.

[16] Kevin Lane Keller. 1993. Conceptualizing, Measuring, and Managing Customer Based Brand Equity. Journal of Marketing 57, 1 (1993), 1-22. http://www.jstor org/stable/1252054

[17] Kevin Lane Keller. 1998. Measuring Customer-Based Brand Equity. Perspectives of Modern Brand Management, ed. Dr Franz-Rudolf Esch 1 (1998), 989-1010.

[18] G. Li, M. McGill, S. Brewster, and F. Pollick. 2020. A Review of Electrostimulationbased Cybersickness Mitigations. In 2020 IEEE International Conference on Artificial Intelligence and Virtual Reality (AIVR). 151-157. https://doi.org/10.1109/ AIVR50618.2020.00034

[19] G. Li, F. M. Varela, A. Habib, Q. Zhang, M. McGill, S. Brewster, and F. Pollick. 2020. Exploring the feasibility of mitigating VR-HMD-induced cybersickness using cathodal transcranial direct current stimulation. In 2020 IEEE International Conference on Artificial Intelligence and Virtual Reality (AIVR). 123-129. https: //doi.org/10.1109/AIVR50618.2020.00030

[20] Mars. 2020. M\&Ms Take Home The Fun Promotion. https://secure. marspromotions.com.au/takehomethefun//FAQ. Accessed: 2020-09-01.

[21] Florian Mathis, Xuesong Zhang, Joseph O'Hagan, Daniel Medeiros, Pejman Saeghe, Mark McGill, Stephen Brewster, and Mohamed Khamis. 2021. Remote XR Studies: The Golden Future of HCI Research? (2021).

[22] Mark McGill, Daniel Boland, Roderick Murray-Smith, and Stephen Brewster. 2015. A Dose of Reality: Overcoming Usability Challenges in VR Head-Mounted Displays. In Proceedings of the 33rd Annual ACM Conference on Human Factors in Computing Systems (Seoul, Republic of Korea) (CHI '15). ACM, New York, NY, USA, 2143-2152. https://doi.org/10.1145/2702123.2702382

[23] Mark McGill and Stephen A. Brewster. 2017. I Am The Passenger: Challenges in Supporting AR/VR HMDs In-Motion. In Proceedings of the 9th International Conference on Automotive User Interfaces and Interactive Vehicular Applications Adjunct (Oldenburg, Germany) (AutomotiveUI '17). Association for Computing Machinery, New York, NY, USA, 251. https://doi.org/10.1145/3131726.3131876

[24] Mark Mcgill, Aidan Kehoe, Euan Freeman, and Stephen Brewster. 2020. Expanding the Bounds of Seated Virtual Workspaces. ACM Trans. Comput.-Hum. Interact. 27, 3, Article 13 (May 2020), 40 pages. https://doi.org/10.1145/3380959

[25] Mark McGill, Alexander Ng, and Stephen Brewster. 2017. I Am The Passenger: How Visual Motion Cues Can Influence Sickness For In-Car VR. In Proceedings of the 2017 CHI Conference on Human Factors in Computing Systems (Denver, Colorado, USA) (CHI '17). Association for Computing Machinery, New York, NY, USA, 5655-5668. https://doi.org/10.1145/3025453.3026046

[26] Mark McGill, Alexander Ng, and Stephen A. Brewster. 2017. How Visual Motion Cues Can Influence Sickness For In-Car VR. In Proceedings of the 2017 CHI Conference Extended Abstracts on Human Factors in Computing Systems (Denver, Colorado, USA) (CHI EA '17). Association for Computing Machinery, New York, NY, USA, 469. https://doi.org/10.1145/3027063.3049790

[27] Mark McGill, John H. Williamson, and Stephen Brewster. 2016. Examining The Role of Smart TVs and VR HMDs in Synchronous At-a-Distance Media Consumption. ACM Trans. Comput.-Hum. Interact. 23, 5, Article 33 (Nov. 2016), 57 pages. https://doi.org/10.1145/2983530

[28] D. Medeiros, R. Anjos, N. Pantidi, K. Huang市, M. Sousa, C. Anslow, and J. Jorge. 2021. Promoting Reality Awareness in Virtual Reality through Proxemics. In 2021 IEEE Conference on Virtual Reality and 3D User Interfaces (VR). 21-30.

[29] Paul Milgram and Herman Colquhoun Jr. 1999. A Taxonomy of Real and Virtual World Display Integration.

[30] Paul Milgram and Fumio Kishino. 1994. A Taxonomy of Mixed Reality Visual Displays. vol. E77-D, no. 12 (12 1994), 1321-1329.

[31] Niantic. 2016. Pokémon Go. Game [iOS, Android].

[32] Donald A. Norman. 2002. The Design of Everyday Things. Basic Books, Inc., USA.

[33] Oculus. 2019. Oculus Guardian. https://developer.oculus.com/documentation/ native/pc/dg-guardian-system/. Accessed: 2020-09-01.

[34] Joseph O'Hagan and Julie R. Williamson. 2020. Reality Aware VR Headsets. In Proceedings of the 9TH ACM International Symposium on Pervasive Displays (Manchester, United Kingdom) (PerDis '20). Association for Computing Machinery, New York, NY, USA, 9-17. https://doi.org/10.1145/3393712.3395334

[35] Joseph O'Hagan, Julie R. Williamson, and Mohamed Khamis. 2020. Bystander Interruption of VR Users. In Proceedings of the 9TH ACM International Symposium on Pervasive Displays (Manchester, United Kingdom) (PerDis '20). Association for Computing Machinery, New York, NY, USA, 19-27. https://doi.org/10.1145/ 3393712.3395339

[36] Philo Tan Chua, R. Crivella, B. Daly, Ning Hu, R. Schaaf, D. Ventura, T. Camill, J. Hodgins, and R. Pausch. 2003. Training for physical tasks in virtual environments:
Tai Chi. In IEEE Virtual Reality, 2003. Proceedings. 87-94.

[37] Jaziar Radianti, Tim A. Majchrzak, Jennifer Fromm, and Isabell Wohlgenannt. 2020. A systematic review of immersive virtual reality applications for higher education: Design elements, lessons learned, and research agenda. Computers \& Education 147 (2020), 103778. https://doi.org/10.1016/j.compedu.2019.103778

[38] Iulian Radu and Bertrand Schneider. 2019. What Can We Learn from Augmented Reality (AR)? Benefits and Drawbacks of AR for Inquiry-Based Learning of Physics. In Proceedings of the 2019 CHI Conference on Human Factors in Computing Systems (Glasgow, Scotland Uk) (CHI '19). Association for Computing Machinery, New York, NY, USA, 1-12. https://doi.org/10.1145/3290605.3300774

[39] D. Raja. 2019. Virtual Reality: Opportunities and Challenges. International fournal for Research in Applied Science and Engineering Technology 7 (04 2019), 1765-1774. https://doi.org/10.22214/ijraset.2019.4321

[40] J.R. Rossiter. 2011. Measurement for the social sciences: The C-OAR-SE method and why it must replace psychometrics. 1-169 pages. https://doi.org/10.1007/978-14419-7158-6

[41] A. L. Simeone. 2016. The VR motion tracker: visualising movement of nonparticipants in desktop virtual reality experiences. In 2016 IEEE 2nd Workshop on Everyday Virtual Reality (WEVR). 1-4. https://doi.org/10.1109/WEVR.2016. 7859535

[42] Maximilian Speicher, Brian D. Hall, and Michael Nebeling. 2019. What is Mixed Reality? (CHI '19). Association for Computing Machinery, New York, NY, USA, 1-15. https://doi.org/10.1145/3290605.3300767

[43] Nancy Staggers and A. F. Norcio. 1993. Mental Models: Concepts for HumanComputer Interaction Research. Int. 7. Man-Mach. Stud. 38, 4 (April 1993), 587-605. https://doi.org/10.1006/imms.1993.1028

[44] Anthony Steed. 2020. Informal Survey of CHI 2019 VR Papers. https://docs.google. com/document/d/1I4401PeZjm7mw0VktRrZ0JozwhHLO0xpdS_xbj-crqI. Accessed: 2020-09-01.

[45] Ivan Sutherland. 2001. The Ultimate Display. Proceedings of the IFIPS Congress 65(2):506-508. New York: IFIP 2 (01 2001).

[46] Ivan E. Sutherland. 1968. A Head-Mounted Three Dimensional Display. In Proceedings of the December 9-11, 1968, Fall foint Computer Conference, Part I (San Francisco, California) (AFIPS '68 (Fall, part I)). Association for Computing Machinery, New York, NY, USA, 757-764. https://doi.org/10.1145/1476589.1476686

[47] H. Tankovska. 2020. Global virtual reality device shipments by vendor 20172019. https://www.statista.com/statistics/671403/global-virtual-reality-deviceshipments-by-vendor/. Accessed: 2020-09-01.

[48] Bruce H. Thomas. 2012. A Survey of Visual, Mixed, and Augmented Reality Gaming. Comput. Entertain. 10, 1, Article 3 (Dec. 2012), 33 pages. https://doi. org $/ 10.1145 / 2381876.2381879$

[49] Alexandra Thompson and Leigh Ellen Potter. 2019. Overlays and Goggles and Projections, Oh My! Exploring Public Perceptions of Augmented Reality Technologies. In Proceedings of the 31st Australian Conference on Human-ComputerInteraction (Fremantle, WA, Australia) (OZCHI'19). Association for Computing Machinery, New York, NY, USA, 295-301. https://doi.org/10.1145/3369457.3369482

[50] Alexandra Thompson and Leigh Ellen Potter. 2020. Defining AR: Public Perceptions of an Evolving Landscape. In Extended Abstracts of the $2020 \mathrm{CHI}$ Conference on Human Factors in Computing Systems (Honolulu, HI, USA) (CHI EA '20). Association for Computing Machinery, New York, NY, USA, 1-8. https: //doi.org/10.1145/3334480.3382843

[51] Valve. 2016. Valve Chaperone. https://support.steampowered.com/kb_article. php?ref=6281-TOKV-4722. Accessed: 2020-09-01.

[52] R. Yu, Z. Duer, T. Ogle, D. A. Bowman, T. Tucker, D. Hicks, D. Choi, Z. Bush, H. Ngo, P. Nguyen, and X. Liu. 2018. Experiencing an Invisible World War I Battlefield Through Narrative-Driven Redirected Walking in Virtual Reality. In 2018 IEEE Conference on Virtual Reality and 3D User Interfaces (VR). 313-319. 